\title{
Setting up a methadone maintenance clinic in a hostel in London's West End
}

\author{
AIMS AND METHOD \\ A satellite methadone prescribing \\ service was set up in a hostel in \\ London's West End. The aim was to \\ investigate if it were feasible to \\ engage and retain these hard-to- \\ reach, chaotic, polydrug users in \\ treatment. A basic needs assessment \\ was undertaken with staff and clients \\ at the hostel. Treatment outcomes
}

\author{
were assessed at 16 weeks using the \\ Maudsley Addiction Profile.
}

\author{
RESULTS \\ At 16 weeks $87 \%$ of the original \\ cohort ( 26 out of 30 ) were still in \\ treatment. There were also signifi- \\ cant reductions in mean heroin use \\ (from 29.7 to 14.5 out of the past 30
}

\author{
days, $P<0.001)$ and in the frequency \\ of injecting (from 25.9 to 15.9 days, \\ $P<0.001)$
}

\begin{abstract}
CLINICAL IMPLICATIONS
This outreach clinic offers a model for developing services to homeless people with substance misuse problems.
\end{abstract}

Heroin use is an independent risk factor for becoming homeless (Caton et al, 2000) and crack (processed cocaine) use is both a predictor of becoming and remaining homeless (Orwin et al, 2005). Homeless people who are engaged with drug/alcohol treatment agencies are more likely to access medical and social care (Nwakeze et al, 2003). Although the best model of service delivery has not been determined, preliminary investigations suggest that outreach work can be successful in engaging this hard-to-reach group (Mistral \& Hollingworth, 2001; Rosenblum et al, 2002). We describe the setting up of such an outreach service in a hostel for the homeless in London's West End.

\section{The service}

The objectives of the pilot scheme were: (a) to engage opiate-dependent hostel residents with a methadone maintenance prescribing service; (b) to reduce drugrelated harm and improve physical and mental health; (c) to reduce the amount of antisocial, street-based activity, such as begging, shoplifting and drug dealing; (d) to move more-stable clients into longer-term treatment with local statutory drug services; (e) to prepare people for moving into second-stage and semi-independent accommodation.

\section{Method}

The manager of a hostel in London's West End approached the substance misuse service of Camden and Islington Mental Health and Social Care Trust for advice when the trust took over the coordination of its on-site needle exchange. The trust's needle exchange coordinator visited the hostel and found that although more than two-thirds of the hostel's residents were intravenous drug users, very few were in treatment with local drug services. This led to a discussion with senior staff in the trust's substance misuse service on how to engage residents with drug treatment services.

\section{The hostel}

The hostel is a stage one hostel which houses 93 homeless people direct from the streets, with referrals coming primarily from the Street Services Team. It is run by the St Mungo's Housing Charity and employs a wide range of specialist staff, including four substance misuse workers who work with residents towards engaging them with treatment services. These are also responsible for running the on-site needle exchange.

\section{Assessing need}

The hostel's substance misuse workers estimated that more than two-thirds of the 93 residents were intravenous drug users, with heroin and crack being the main drugs of choice. Very few residents were alcohol dependent. Staff confirmed that only 10 residents were in treatment with local prescribing services. They felt that statutory drug services had failed to meet the needs of their clients, many of whom had been in treatment in the past but had been prematurely discharged because of repeated lateness or missed appointments. The highly structured programmes offered by drug services were considered inappropriate for homeless people with chaotic lifestyles and multiple needs.

We undertook a survey of residents as they entered the treatment programme to gauge their views on why previous treatment episodes had failed and what were the perceived problems with existing statutory drug services. The main barriers identified were long waiting times for treatment, difficulties in keeping fixed appointments, a feeling of being messed about by services and sanctions imposed for continued heroin use while on a methadone maintenance programme. The new service works to a harm reduction model and, although clients are encouraged to reduce and stop illicit drug use and heavy alcohol consumption, sanctions are not imposed for continued opiate use. 


\section{Seeking funding}

original papers
We approached our commissioners to discuss the possibility of developing a satellite prescribing clinic at the hostel. They suggested we put in an expression of interest for the next round of Health Action Zone funding for a pilot scheme aimed at assessing the feasibility of engaging and retaining this client group in methadone maintenance treatment.

The bid was successful and the service began in February 2003. The initial funding allowed for a maximum of 30 treatment places for methadone maintenance for a pilot phase of 6 months. If the scheme were a success, the commissioner and drug action team coordinator indicated they would continue the service through mainstream funding.

\section{The service}

The satellite clinic is held in the treatment room and a counselling room at the hostel on two mornings a week and is manned by a staff grade doctor and two nurses. The initial comprehensive assessment is undertaken by the hostel's substance misuse workers. At the start of the pilot scheme, they were also responsible for prioritising the 30 most needy clients for treatment based on length of stay, poor physical and mental health, a history of poor engagement with drug treatment services and a history of street-based, antisocial behaviour. At the first appointment the doctor and one of the nurses complete the standardised initial medical assessment and common assessment forms (CAFs). The CAF incorporates the Maudsley Addiction Profile (MAP; Marsden et al, 1998) - a psychometrically standardised and validated outcome measure developed for the National Treatment Outcome Research Study (Gossop et al, 1998). Review forms also include the MAP (conducted at 8 weeks, 6 months and 1 year). The main areas of interest are substance use, health risk behaviour, health symptoms, personal/social functioning, legal issues and success in goal achievement as set by the keyworker and client.

After the initial assessment, residents provide a urine specimen under supervision; this is tested for opiates on-site with dipsticks and then sent for confirmatory analysis at the local laboratory. Residents have their first dose of methadone prescribed on the day of the initial medical assessment. Thereafter, doses are reviewed twice weekly and titrated upwards until an optimised dose has been achieved. Consumption of medication is supervised at a nearby community pharmacy. The pharmacy is not open at weekends, so residents are given doses to take away for these 2 days. To reduce the risk of theft, all residents on the scheme are given a secure safe in which to store their medication. If residents need 7-day-a-week supervised consumption, this can be arranged at another high-street pharmacy.

The senior nurse responsible for the day-to-day running of the programme previously worked in a West End needle exchange and is a familiar face to many on the programme. The staff grade psychiatrist previously worked in general practice - experience that has proved invaluable in dealing with the numerous physical complications that these people experience. Every 2 weeks a multidisciplinary team meeting is held at the hostel, which the consultant attends.

In addition to the input from the substance misuse nurses and doctor, all residents on the scheme have a drugs worker at the hostel who is available for individual sessions. These workers also run groups for the residents and liaise with other specialist workers and outside agencies.

\section{Results}

\section{Clients}

Of the initial 30 clients, 24 were male and 6 were female with an age range of 19-47 years (mean 33 years). The ethnic origin was White British $(n=18)$, Irish $(n=4)$ or other $(n=8)$. At the time of assessment, the mean number of days on which heroin had been used in the past 30 was 29.7 (range 0-30 days - 0 being for a client buying illicit methadone). The mean amount of money spent on heroin per day was $\mathrm{f65.50}$ (range $\mathrm{f} 10-200$ ). The majority were injecting heroin (83\%), averaging 6 injections per day. Out of the 30 clients, 24 reported using crack cocaine in addition to heroin, and had used crack on a mean of 26.8 days out of the last 30 .

\section{Outcomes}

Using the MAP at the time of initial assessment and again at 16 weeks, we investigated the initial impact of treatment. Heroin use fell from a mean of 29.7 days out of the last 30 to 14.5 days ( $t=6.82$, d.f. $=27, P<0.001$ ), with the amount of money spent on heroin falling from a mean of $f 65.5$ to $f 24.9$ ( $t=5.27$, d.f. $=11, P<0.001)$.

For those using crack cocaine, there was a fall in use from a mean of 26.8 to 22 days out of the last $30(t=2.9$, d.f. $=22, P<0.01$ ). There was a non-significant drop in the mean amount spent on a typical day when using crack (from $f 57$ to $f 42$ ). Other drug use (mainly alcohol, cannabis and tobacco) was largely unchanged. The number of days out of the last 30 on which the patients had injected drugs fell from a mean of 25.9 to 15.9 ( $t=5.06$, d.f. $=23, P<0.001)$ and the number of injections per day fell from a mean of 6 to $2.7(t=4.16$, d.f. $=23$, $P<0.001)$. Scores for psychological and physical health symptoms were largely unchanged. There were insufficient data on criminal activity and psychosocial functioning for analysis.

\section{Engagement}

At 8 weeks almost all clients $(28,93 \%)$ were still in treatment and at 16 weeks $26(87 \%)$ remained in treatment. Of the 4 discharged at 16 weeks, 1 was in prison and another booked out of the hostel but was offered several follow-up appointments before being given a methadone reduction prescription. Two clients failed to collect their methadone for more than 4 days and so were invited to see the doctor to re-engage. The 1 client 
who took up this offer was no longer using opiates. The rate of attendance at the pharmacy for supervised doses of methadone was extremely high at over $96 \%$.

Of the original cohort of 30 clients, 11 had moved on by the 16 -week evaluation. Three had successfully engaged with the local mainstream drug service, 5 had been rehoused in stage two hostels or semi-independent accommodation and their treatment was transferred to local drug services, and 3 had gone into residential detoxification and rehabilitation.

\section{Discussion}

It is estimated that there are about 1000 people living in hostels in Camden alone, with two large hostels that house between 200 and 500 people. The success of the satellite prescribing service described here leads us to believe that this model of service delivery could be replicated in other large hostels both in London and other cities around the country.

The service won a Care Trust Award for the most innovative new service by the Camden and Islington Mental Health and Social Care Trust and a runners-up Andy Ludlow Award, which recognises innovation in tackling homelessness in London. When presenting the service, the manager of the hostel stated that one of the key reasons he felt that the scheme had been a success was because staff had been willing to go the extra distance for clients and were genuinely concerned about their well-being.

\section{Declaration of interest}

None.

\section{Acknowledgements}

Dr Michael Haskew was the original staff grade doctor working at the clinic and undertook most of the interviews. We would like to thank all the drugs workers and managers at the hostel who have worked closely with us over the past 2 years.

\section{References}

CATON, C. L., HASIN, D., SHROUT, P. E. et al (2000) Risk factors for approach with opiate-dependent, homelessness among indigent urban adults with no history of psychotic illness: a case control study. American Journal of Public Health, 90, 258-263.

GOSSOP, M., MARSDEN, J. \& STEWART D. (1998) NTORS at OneYear: the National Treatment Outcome Research

Study - Changes in Substance Use, Health and Criminal Behaviours One YearAfter Intake. London: Department of Health.

MARSDEN, J., GOSSOP, P. M., STEWART, D., et al (1998) The Maudsley Addiction Profile (MAP): a brief instrument for assessing treatment outcome. Addiction, 93, 1857-1867.

MISTRAL, W. \& HOLLINGWORTH, M. (2001) The supervised methadone and resettlement team nurse: an effective homeless people. International Nursing Review, 48, 122-128.

NWAKEZE, P. C., MAGURA, S., ROSENBLUM, A., et al (2003) Homelessness, substance misuse, and access to public entitlements in a soup kitchen population. Substance Use and Misuse, 38, 645-668.

ORWIN, R. G., SCOTT, C. K. \& ARIEIRA C. (2005) Transitions through homelessness and factors that predict three-year treatment outcomes. Journal of Substance Abuse Treatment, 28 (suppl. 1), S23-\$39.

ROSENBLUM, A., NUTTBROCK, L. McQUISTION, H., et al (2002) Medical outreach to homeless substance users in NewYork City: preliminary results.

Substance Use and Misuse, 37, 1269-1273.

*John Dunn Lead Consultant in Substance Misuse, Camden and Islington Mental Health and Social CareTrust, 457 Finchley Road, London NW3 6HN, email: john.dunn@royalfree.nhs.uk, David Robertson Harm Reduction Clinical Nurse Specialist, South Camden Drug Service, Margarete Centre, Paul Davis Head of Psychology, Camden and Islington Substance Misuse Services, Margarete Centre, Babak Khosrawan Staff Grade Psychiatrist, North Camden Drug Service, Suneel Christian Nurse, South Camden Drug Service, Margarete Centre, London. original

papers 